\title{
Psychometric Properties of the Polish Version of the Diabetes Distress Scale (DDS)
}

\author{
Sylwia Krzemińska (iD) \\ Ewelina Bąk (D) ${ }^{2}$ \\ 'Department of Clinical Nursing, Faculty \\ of Health Science, Medical University in \\ Wroclaw, Wroclaw, Poland; \\ ${ }^{2}$ Department of Nursing, Faculty of \\ Health Sciences, University of Bielsko- \\ Biala, Bielsko-Biała, Poland
}

Background: Type 2 diabetes is a disease that affects the functioning and life of both the patient and their family. It involves the constant treatment, self-care, monitoring of blood glucose levels and adherence to physical activity recommendations. As a result, it causes discomfort, distress and reduces the quality of life.

Aim: Due to the lack of a scale that would precisely evaluate the level of distress in patients with diabetes in Poland, we decided to linguistically adapt the DDS scale to the Polish population and investigate its psychometric properties in relation to Polish patients.

Material: The study group consisted of 336 individuals in total, including 156 females (46.43\%) and 180 males (53.57\%), aged $59.13 \pm 8.4$ on average. The patients were under the care of a specialist diabetes clinic. The research tool was the Diabetic Stress Scale (DDS).

Results and Conclusion: Our analysis showed that the reliability of both the scale and its components was at a good level. Only the RD-related part was characterised by a lower Cronbach's alpha coefficient of 0.614. The DDS scale can be successfully used for the assessment of distress in the Polish population of patients with type 2 diabetes.

Keywords: diabetes, distress, depression

\section{Background}

DM constitutes a significant global health problem and is among the most frequent causes of death. According to the literature, there were 463 million diabetes patients in 2019, and the number will increase to 700 million by $2045 .{ }^{1}$ The incidence of the disease varies across continents, depending on the presence of associated risk factors.

Type 2 diabetes is a disease that affects the functioning and life of both the patient and their family. It involves the constant treatment, self-care, monitoring of the level of glucose and adhering to the recommendations related to physical activity. Despite the help of diabetes specialists, patients have to make most of the urgent, treatment-related decisions on their own, which causes frustration and reduces their quality of life. ${ }^{2}$

It is not surprising that mental suffering is particularly common in diabetes patients, especially those dependent on others and lacking the means and possibility to function independently. ${ }^{3,4}$ The duration of the disease is also irrelevant as the related distress is already caused by the diagnosis itself and the awareness of possible complications. ${ }^{5}$

Patients with diabetes develop depressive disorders, even though they are not necessarily clinically diagnosed with depression, and certainly show an increased level of emotional stress related to diabetes-related fears and concerns. ${ }^{6,7}$
Correspondence: Sylwia Krzemińska Department of Clinical Nursing, Faculty of Health Sciences, Wroclaw Medical University, ul. K. Bartla 5, Wroclaw, 51-618, Poland

Email sylwia.krzeminska@umed.wroc.pl 
The Diabetes Distress Scale (DDS) is a tool developed by Polonsky et $\mathrm{al}^{8}$ based on the Questionnaire on Stress in Patients with Diabetes-Revised (QSD-R) ${ }^{9}$ and the Problem Areas in Diabetes Scale (PAID). ${ }^{3}$ It is a short tool for the assessment of diabetes-related emotional stress which identifies patients' distress associated with the treatment, emotional burden, social support and the availability of medical care. DDS measures four various dimensions of distress: 1) regime-related distress; 2) physician-related distress; 3) emotional burden and 4) interpersonal distress. ${ }^{3,10}$

DDS was developed in the United States but it was also linguistically and psychometrically adapted to other populations: Danish, Norwegian, Chinese and Thai. ${ }^{11-14}$

\section{Aim}

Since there are no reliable scales that would precisely assess the level of distress in patients with diabetes in Poland, we decided to linguistically adapt the DDS scale to the Polish population and investigate its psychometric properties in relation to Polish patients.

\section{Methods}

The study was conducted from January to December 2019 at the University Clinical Hospital in Wroclaw, Poland. The sample consisting of 336 patients with type 2 diabetes (mean age $59.13 \pm 8.4$ years) was recruited from among 380 patients who had been suffering from diabetes for at least 5 years. The recruitment process is presented in a diagram (Figure 1).

According to the data of the National Health Fund and the Diabetes Coalition, it is estimated that there are approx. 3.5 million people with diabetes in Poland, which constitutes $9 \%$ of the entire population. T2DM has been diagnosed in 2 million patients, which constitutes $6 \%$ of the whole population. Given the fact that $6 \%$ of the population in Poland has T2DM (assuming a maximum error of 3\% and a confidence interval of 90), it was estimated that the sample should include a minimum of 163 individuals. Therefore, the size of the sample used in the study was deemed sufficient.

\section{Inclusion Criteria}

The following inclusion criteria were applied: age $>18$, at least 5 years since the diagnosis of type 2 diabetes, lack of diagnosed cognitive disorders, patient's consent to participate in the study.

\section{Exclusion Criteria}

Age $<18$ years, less than 5 years since the diagnosis, documented cognitive impairment, lack of consent to participate in the study.

\section{Ethics}

The study was approved by the Bioethics Committee of the Wroclaw Medical University (KB approval No. - 622/ 2018). All patients gave their informed consent to participate in the study and were informed that they could withdraw their participation at any time. The report from the study complied with the principles of the Helsinki Declaration and the guidelines of Good Clinical Practice.

\section{Research Instrument}

The DDS tool consists of 17 items and four dimensions: emotional burden EB (five items), physician-related distress PD (four items), regimen-related distress RB (five items) and diabetes-related interpersonal distress ID (three items). The items are measured using the 6-point Likert scale, from 1 (no problems) to 6 (severe problems), based

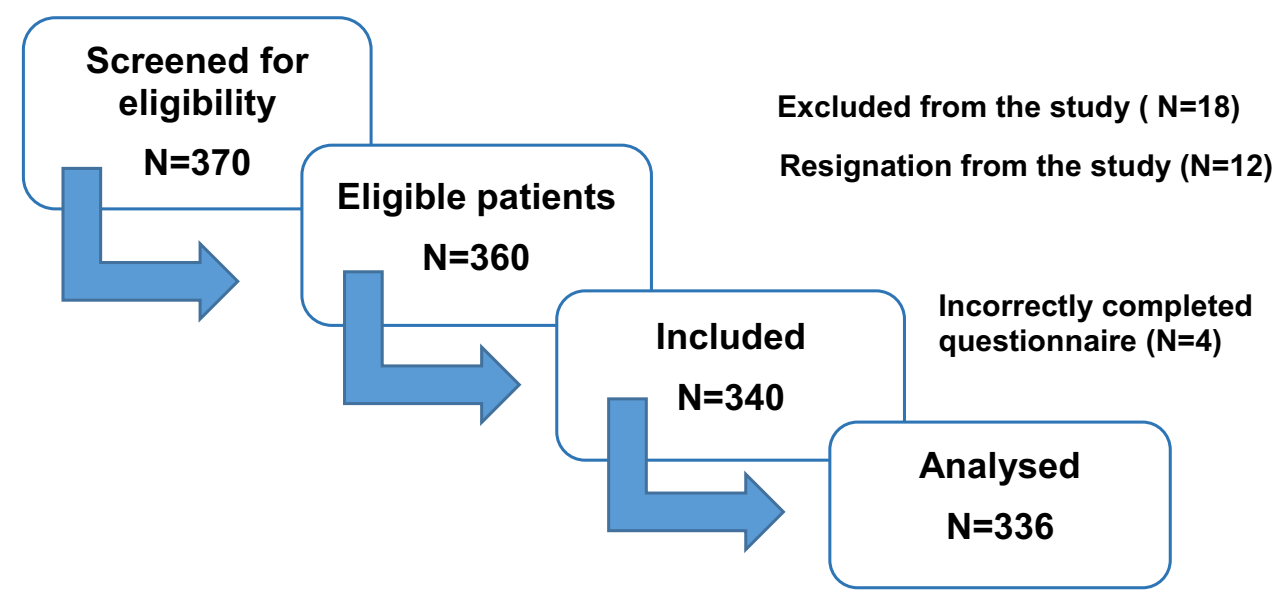

Figure I The recruitment process. 
on the degree to which each item currently poses a problem in the participant's life. It was demonstrated that the original version of DDS is reliable (Cronbach's alpha $=0.93) .{ }^{8}$ The mean score for total distress was calculated by dividing the total score by 17 . Each subscale of a specific domain was calculated by dividing the total score of the subscale by the number of questions relating thereto. With the possible range of 1 to 6 , total DDS and each of its components were evaluated using the mean scores $<2$ indicating that there was no distress, mean scores between 2 and 2.9 indicating moderate distress, mean scores $\geq 3$ indicating a high level of distress.

The tool was made available to the authors of the Polish version by the Behavioral Diabetes Institute in San Diego. A panel of experts (including one diabetes educator, one nurse from a diabetes unit and one physician) reviewed the completed translation. The team discussed discrepancies between the original and the obtained version of the questionnaire and reached a consensus. The pilot test was conducted on a pilot group consisting of 10 adults with type 2 diabetes from PHC. The participants were asked to read the questions and verbally assess their clarity. No changes were made as no problems were noted. The participants of the pilot test were not included in the study group.

\section{Data Analysis}

Internal consistency was evaluated using Cronbach's alpha, total correlation and confirmatory factor analysis (CFA). Since the DDS items are expressed on an ordinal, not continuous scale, parameters were evaluated using the Diagonally Weighted Least Squares method. The level of significance in the analysis was set at 0.05 . Therefore, all $\mathrm{p}$ values below 0.05 were considered to indicate significant relationships. The analysis was conducted with the use of the $\mathrm{R}$ software, version 3.6.0. ${ }^{15,16}$

\section{Results}

The study group consisted of 336 individuals in total, including 156 females $(46.43 \%)$ and 180 males (53.57\%), aged 59.13 \pm 8.4 years on average. Most participants had vocational $(157,46.73 \%)$ or secondary 106 $(31.55 \%)$ education, and were in relationships 283 $(84.23 \%)$. Most patients were also professionally active $243(72.32 \%)$ and residing in the country $243(72.32 \%)$.

In $294(87.50 \%)$ individuals the disease was diagnosed 5-10 years earlier, while 42 (12.5) participants were suffering from diabetes for more than 10 years. As many as
$222(66.07 \%)$ individuals were receiving treatment with oral antidiabetic medications, $77(22.92 \%)$ were treated with insulin and 37 were receiving combination treatment (11.01\%). Diabetes was accompanied by hypertension in 140 patients $(41.67 \%)$, eye diseases in 84 patients $(25.00 \%)$, ischemic heart disease in 55 patients $(16.37 \%)$ and renal failure in 27 patients $(8.04 \%)$.

Specialists diagnosed the following complications of diabetes: retinopathy in 90 patients (26.79\%), diabetic neuropathy in 54 patients (16.07\%), nephropathy in 30 patients $(8.93 \%)$ and diabetic foot syndrome in 12 patients (3.57\%) (Table 1).

The DDS questionnaire enables the assessment of the level of diabetes-related distress along with its four components. The score in each scale is the average of the items included in it, namely a number from 1 to 6 . Higher scores indicate an increased level of diabetes-related stress. The scores were interpreted according to the following key for the scale: - scores $<2$ points indicate the normal level of distress, scores $>2$ to 2.9 points indicate moderate distress and scores $>3$ to 6 points indicate severe distress (ie a level of distress that requires medical attention). ${ }^{5}$

In the Total diabetes-related distress item, the level of distress was high in 190 out of 336 study participants $(56.55 \%)$, moderate - in 128 subjects $(38.10 \%)$, and normal - in 18 individuals (5.36\%).

In the Emotional burden (EB) item, distress was severe in $177(52.68 \%)$ out of 336 participants, moderate - in 111 subjects (33.04\%) and normal - in 48 subjects (14.29\%).

In the Physician-related distress (PD) item, distress was severe in $248(73.81 \%)$ out of 336 participants, moderate in 59 patients $(17.56 \%)$, and the condition of 29 patients was normal $(8.63 \%)$.

In the Regimen-related distress (RD) item, distress was moderate in $157(46.73 \%)$ out of 336 participants, severe - in 132 subjects (39.29\%), and normal in 47 patients $(13.99 \%)$.

In the Diabetes-related interpersonal distress item, the level of distress was normal in 129 (38.39\%) out of 336 participants, moderate - in 107 subjects (31.85\%) and severe - in 100 individuals (29.76\%) (Table 2).

\section{Analysis of Individual Items}

The floor effect is the percentage of the respondents who selected the answer with the lowest score in a given question. The ceiling effect, on the other hand, is the percentage of respondents who selected the answer with the highest score in a given question. A high floor or ceiling effect in a given question indicates that it may not be 
Table I Characteristics of the Study Group

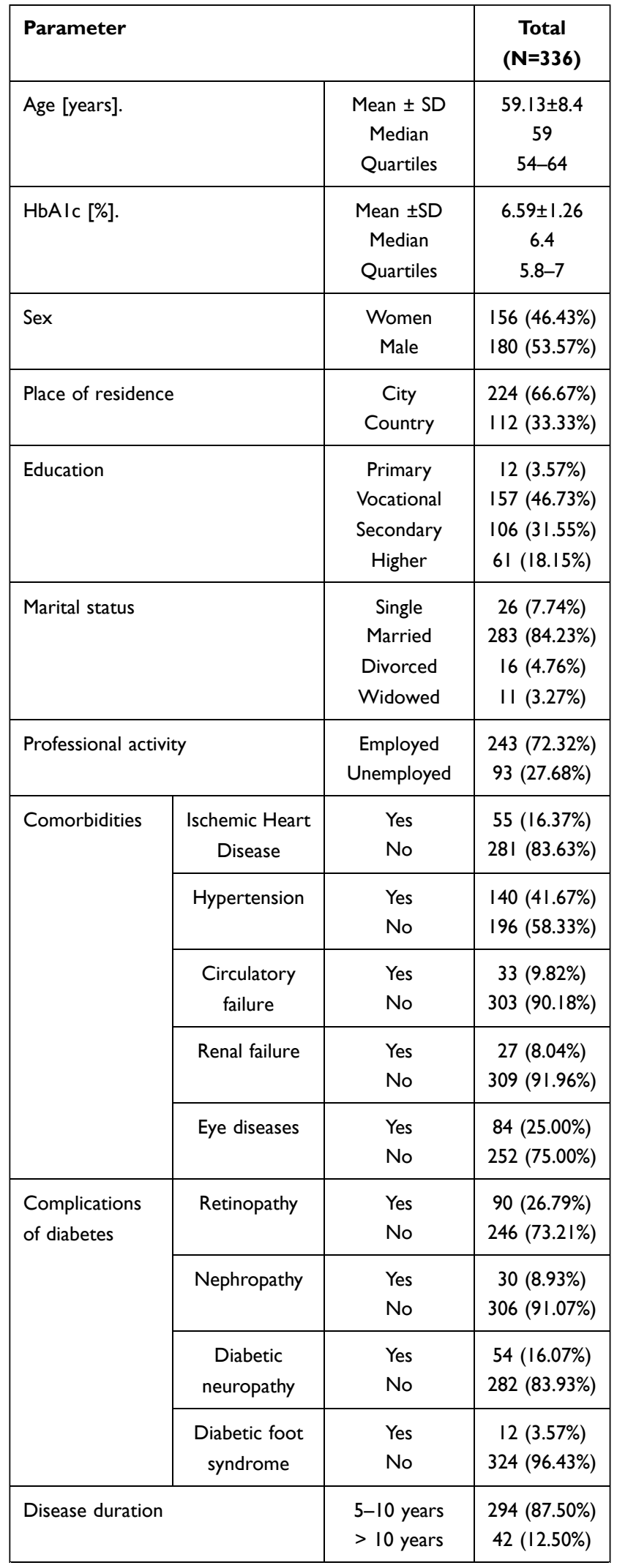

(Continued)
Table I (Continued).

\begin{tabular}{|l|c|c|}
\hline Parameter & $\begin{array}{c}\text { Total } \\
(\mathbf{N}=336)\end{array}$ \\
\hline Treatment & $\begin{array}{c}\text { Oral } \\
\text { medication } \\
\text { Insulin } \\
\text { Combination } \\
\text { treatment }\end{array}$ & $222(66.07 \%)$ \\
& $37(22.92 \%)$ \\
\hline
\end{tabular}

Abbreviation: SD, standard deviation.

entirely suitable for the analysed population. No floor/ ceiling effects were observed in the study group (Table 3).

\section{Reliability of the Tool Confirmatory Factor Analysis}

Since the DDS items are expressed on an ordinal, not continuous scale, the authors applied the Diagonally Weighted Least Squares method.

The original structure of DDS is based on four factors (plus the total score) (Table 4).

For this structure, the obtained values of fit indices RMSEA, CFI and TLI were unsatisfactory. However, the SRMR value indicated that the model was well-adjusted to the data (the exact values are described as Model I in Table 5).

Since no direct confirmation of the 4-factor structure of DDS was obtained, the authors applied modifications indicated by the so-called modification indices. In this case, they suggest that correlations between the following item pairs must be introduced into the model: 1 and 5, 6 and 12, 8 and 12 .

It enables obtaining the desired parameter values (SRMR $<0.09$, CFI $>0.96$, model II in the Table 5).

Since all the correlations included in the model combine items belonging to the same subscale, they do not change the factor structure of DDS.

Loadings of particular items ranged from 0.383 to 0.779 and were statistically significant $(\mathrm{p}<0.05)$ (Table 6). Loadings are interpreted as correlations of items with the subscale to which they belong. Their significance means that all items significantly correlate with the score of "their" subscale (loadings are frequently referred to as the CFA-implied item-total correlations).

\section{Internal Consistency}

Internal consistency was assessed using Cronbach's $\alpha$ to determine whether all items on the multi-item scale 
Table 2 Characteristics of the DDS Scales

\begin{tabular}{|l|c|c|c|c|c|}
\hline \multirow{2}{*}{$\begin{array}{l}\text { Level of Diabetes- } \\
\text { Related Distress n (\%) }\end{array}$} & \multicolumn{5}{|c|}{ Domain of Distress } \\
\cline { 2 - 6 } & $\begin{array}{c}\text { Total Diabetes- } \\
\text { Related Distress }\end{array}$ & $\begin{array}{c}\text { Emotional } \\
\text { Burden (EB) }\end{array}$ & $\begin{array}{c}\text { Physician-Related } \\
\text { Distress (PD) }\end{array}$ & $\begin{array}{c}\text { Regimen-Related } \\
\text { Distress (RD) }\end{array}$ & $\begin{array}{c}\text { Diabetes-Related } \\
\text { Interpersonal } \\
\text { Distress (ID) }\end{array}$ \\
\hline Normal condition & $18(5.36 \%)$ & $48(14.29 \%)$ & $29(8.63 \%)$ & $47(13.99 \%)$ & $129(38.39 \%)$ \\
Moderate distress & $128(38.10 \%)$ & $111(33.04 \%)$ & $59(17.56 \%)$ & $157(46.73 \%)$ & $100(29.76 \%)$ \\
High distress & $190(56.55 \%)$ & $177(52.68 \%)$ & $248(73.81 \%)$ & $132(39.29 \%)$ & $107(31.85 \%)$ \\
\hline
\end{tabular}

Table 3 The Floor and the Ceiling Effect in the Study Group

\begin{tabular}{|l|c|c|c|}
\hline Item & Floor Effect & Ceiling Effect & No Data \\
\hline 1 & $9.8 \%$ & $20.5 \%$ & $0.0 \%$ \\
2 & $15.8 \%$ & $8.3 \%$ & $0.0 \%$ \\
3 & $17.9 \%$ & $5.7 \%$ & $0.0 \%$ \\
4 & $18.5 \%$ & $4.2 \%$ & $0.0 \%$ \\
5 & $5.7 \%$ & $7.7 \%$ & $0.0 \%$ \\
6 & $25.6 \%$ & $2.7 \%$ & $0.0 \%$ \\
7 & $4.5 \%$ & $12.5 \%$ & $0.0 \%$ \\
8 & $12.5 \%$ & $3.0 \%$ & $0.0 \%$ \\
9 & $28.3 \%$ & $4.5 \%$ & $0.0 \%$ \\
10 & $26.5 \%$ & $2.4 \%$ & $0.0 \%$ \\
11 & $9.8 \%$ & $9.8 \%$ & $0.0 \%$ \\
12 & $13.1 \%$ & $3.6 \%$ & $0.0 \%$ \\
13 & $24.7 \%$ & $5.1 \%$ & $0.0 \%$ \\
14 & $17.9 \%$ & $6.5 \%$ & $0.0 \%$ \\
15 & $8.9 \%$ & $7.1 \%$ & $0.0 \%$ \\
16 & $15.8 \%$ & $3.3 \%$ & $0.0 \%$ \\
17 & $19.9 \%$ & $4.5 \%$ & $0.0 \%$ \\
\hline
\end{tabular}

Table 4 Original Structure of DDS

\begin{tabular}{|l|c|}
\hline Domain & Items \\
\hline Emotional burden (EB) & $2,4,7,10,14$ \\
Physician-related distress (PD) & $1,5,11,15$ \\
Regimen-related distress (RD) & $3,6,8,12,16$ \\
Diabetes-related interpersonal distress (ID) & $9,13,17$ \\
\hline
\end{tabular}

Table 5 Correlation Models

\begin{tabular}{|l|c|c|c|c|c|c|c|}
\hline \multirow{2}{*}{ Model } & \multicolumn{2}{|c|}{$\begin{array}{c}\text { Chi-Squared } \\
\text { Test }\end{array}$} & RMSEA & CFI & TLI & SRMR \\
\cline { 2 - 7 } & $\chi^{2}$ & df & p & & & & \\
\hline I & 317.145 & $I I 5$ & 0 & 0.072 & 0.954 & 0.946 & $0.08 I$ \\
II & 274.689 & $I I 2$ & 0 & 0.066 & 0.963 & 0.955 & 0.075 \\
\hline
\end{tabular}

measured the same concept. It was calculated for the entire tool and each subscale. The total score of DDS and 3 out of 4 subscales was $>0.7$. Only the Regimen-related distress $(\mathrm{RD})$ subscale scored $<0.7$.
Table 6 Loadings of Particular Items in the DDS Scale

\begin{tabular}{|l|c|c|c|}
\hline Domain & Item & Loading & $\mathbf{P}$ \\
\hline Emotional burden (EB) & 2 & 0.662 & $\mathrm{P}<0.00 \mathrm{I}$ \\
& 4 & 0.679 & $\mathrm{P}<0.00 \mathrm{I}$ \\
& 7 & 0.530 & $\mathrm{P}<0.00 \mathrm{I}$ \\
& 10 & 0.586 & $\mathrm{P}<0.00 \mathrm{I}$ \\
& 14 & 0.653 & $\mathrm{P}<0.00 \mathrm{I}$ \\
\hline Physician-related distress (PD) & $\mathrm{I}$ & 0.552 & $\mathrm{P}<0.00 \mathrm{I}$ \\
& 5 & 0.744 & $\mathrm{P}<0.00 \mathrm{I}$ \\
& $1 \mathrm{I}$ & 0.749 & $\mathrm{P}<0.00 \mathrm{I}$ \\
& 15 & 0.680 & $\mathrm{P}<0.00 \mathrm{I}$ \\
\hline Regimen-related distress (RD) & 3 & 0.568 & $\mathrm{P}<0.00 \mathrm{I}$ \\
& 6 & 0.403 & $\mathrm{P}<0.00 \mathrm{I}$ \\
& 8 & 0.568 & $\mathrm{P}<0.00 \mathrm{I}$ \\
& 12 & 0.383 & $\mathrm{P}<0.00 \mathrm{I}$ \\
& 16 & 0.524 & $\mathrm{P}<0.00 \mathrm{I}$ \\
\hline Diabetes-related interpersonal & 9 & 0.713 & $\mathrm{P}<0.00 \mathrm{I}$ \\
distress (ID) & 13 & 0.779 & $\mathrm{P}<0.00 \mathrm{I}$ \\
& 17 & 0.675 & $\mathrm{P}<0.00 \mathrm{I}$ \\
\hline
\end{tabular}

Values of Cronbach's alpha for particular subscales are presented in Table 7.

An adjusted item-sum correlation was also performed. The adjusted item-sum correlations were first used to identify the items that were not in agreement with other items in the questionnaire. The item-sum correlations should be $>0.4$ to be considered acceptable The impact of removing a single item on Cronbach's $\alpha$ coefficient was also determined. Removal of none of the items improved the reliability of the Regimen-related distress (RD) subscale (Table 8).

\section{Content Validity}

The original DDS seemed acceptable, and no cultural or language-related differences are visible between Poland and the home country of the creators of DDS in terms of distress caused in patients with type 2 diabetes. 
Table 7 Cronbach's Alpha for Individual Parts and the Entire DDS

\begin{tabular}{|l|c|}
\hline Domain & Cronbach's Alpha \\
\hline Total diabetes-related distress & 0.880 \\
Emotional burden (EB) & 0.756 \\
Physician-related distress (PD) & 0.801 \\
Regimen-related distress (RD) & 0.614 \\
Diabetes-related interpersonal distress (ID) & 0.766 \\
\hline
\end{tabular}

\section{Discussion}

The paper aimed to adapt and test psychometric properties of the Polish version of the DDS questionnaire for patients with diabetes. The questionnaire was developed based on the DRD theory. The tool measures emotional burden (EB), physician-related distress (PD), regimen-related distress (RD) as well as diabetes-related interpersonal distress (ID).

As it is commonly known, diabetes is a chronic disease that requires patients to be highly involved in the whole process of treatment, which comprises physical activity, proper dietary regimen and pharmacological treatment. If left untreated, diabetes leads to serious complications. As a consequence, patients must be always vigilant and attentive to what they do. Diabetes patients are at risk of both depressive states and they fear for their own health and even life. Therefore, it seems important to pay greater attention to their mental condition to identify emotional problems before they evolve into depressive disorders.

Our analysis showed that the reliability of both the scale and its individual components was at a good level. Only the RD-related part was characterised by a lower Cronbach's alpha coefficient of 0.614. The authors of the study concerning the original scale obtained similar $\alpha$ values for the sample: a 17 - point scale in total $=0.93$; $\mathrm{EB}=0.88, \mathrm{PD}=0.88, \mathrm{RD}=0.90$ and $\mathrm{ID}=0.88 .^{8}$

Accuracy of the content, as well as reliability and accuracy of the structure, were demonstrated for the original version. It was also established that the measurement model is generalised. Published studies in which the questionnaire was used in non-baseline populations also show a good level of accuracy and reliability. 5,17-19,

A study among Malay patients with T2D showed that the MDDS-17 had high internal consistency (0.94), ${ }^{17}$ which is comparable to that of the original DDS-17 (0.93). ${ }^{8}$

In the Mexican version (DSDH17M), the 17-item structure was also retained, but the scale was divided into 3 subscales: the first, combined - Regimen-related distress and Emotional burden (RD + EB), the second
Table 8 Item-Sum Correlations for DDS

\begin{tabular}{|c|c|c|c|}
\hline Subscale & Item & $\begin{array}{c}\text { Alpha } \\
\text { After Item } \\
\text { Exclusion }\end{array}$ & $\begin{array}{c}\text { Discriminatory } \\
\text { Power }\end{array}$ \\
\hline $\begin{array}{l}\text { Total diabetes-related } \\
\text { distress }\end{array}$ & $\begin{array}{l}1 \\
2 \\
3 \\
4 \\
5 \\
6 \\
7 \\
8 \\
9 \\
10 \\
11 \\
12 \\
13 \\
14 \\
15 \\
16 \\
17\end{array}$ & $\begin{array}{l}0.877 \\
0.873 \\
0.873 \\
0.873 \\
0.871 \\
0.878 \\
0.875 \\
0.874 \\
0.872 \\
0.875 \\
0.871 \\
0.879 \\
0.870 \\
0.872 \\
0.874 \\
0.874 \\
0.874\end{array}$ & $\begin{array}{l}0.448 \\
0.537 \\
0.531 \\
0.546 \\
0.588 \\
0.407 \\
0.475 \\
0508 \\
0.567 \\
0.479 \\
0.578 \\
0.380 \\
0.612 \\
0.552 \\
0.510 \\
0.512 \\
0.523\end{array}$ \\
\hline Emotional burden (EB) & $\begin{array}{c}2 \\
4 \\
7 \\
10 \\
14\end{array}$ & $\begin{array}{l}0.689 \\
0.682 \\
0.764 \\
0.702 \\
0.716\end{array}$ & $\begin{array}{l}0.586 \\
0.607 \\
0.359 \\
0.552 \\
0.516\end{array}$ \\
\hline $\begin{array}{l}\text { Physician-related } \\
\text { distress (PD) }\end{array}$ & $\begin{array}{c}1 \\
5 \\
11 \\
15\end{array}$ & $\begin{array}{l}0.749 \\
0.683 \\
0.778 \\
0.789\end{array}$ & $\begin{array}{l}0.625 \\
0.762 \\
0.558 \\
0.534\end{array}$ \\
\hline $\begin{array}{l}\text { Regimen-related } \\
\text { distress (RD) }\end{array}$ & $\begin{array}{c}3 \\
6 \\
8 \\
12 \\
16\end{array}$ & $\begin{array}{l}0.557 \\
0.558 \\
0.584 \\
0.576 \\
0.524\end{array}$ & $\begin{array}{l}0.376 \\
0.374 \\
0.319 \\
0.337 \\
0.440\end{array}$ \\
\hline $\begin{array}{l}\text { Diabetes-related } \\
\text { interpersonal } \\
\text { distress (ID) }\end{array}$ & $\begin{array}{c}9 \\
13 \\
17\end{array}$ & $\begin{array}{l}0.659 \\
0.701 \\
0.693\end{array}$ & $\begin{array}{l}0.622 \\
0.583 \\
0.592\end{array}$ \\
\hline
\end{tabular}

Diabetes-related interpersonal distress (ID), and the third Physician-related distress (PD). Internal consistency for the entire scale was $0.91 .^{18}$

A similar breakdown applies to the Chinese version (CDDS-15). In the studies on the Chinese population, the Cronbach's $\alpha$ coefficient for internal consistency of the entire scale was 0.90 , but in the Chinese version, 2 questions were eliminated. ${ }^{14}$

In the studies on the diabetic population in Chile, ${ }^{20}$ the structure of 4 subscales was left, but as many as 4 
questions were eliminated, which resulted in the final retention of only 13 items. The overall reliability of the tool in the 13-item version was considered adequate (0.742), however, it is lower than in the Polish, Danish ${ }^{11}$ or Norwegian ${ }^{13}$ studies.

\section{Limitations, Implications, and Suggestions for Future Research}

There were certain limitations to the study. The group consisted of patients from one diabetes treatment centre. Even though patients admitted to the centre come from the entire voivodship at least, it does not fully reflect the entire population. The recruited patients were also under constant care of a specialist clinic (regular visits to the doctor every three months). Perhaps the results would be different for patients under the care of a Primary Care Physician.

\section{Implications}

The DDS questionnaire makes it possible to identify patients' problems in three areas: emotional burden, regimen-related and physician-related distress as well as interpersonal distress. Once the area of distress is identified, the medical team can refer to it when they are communicating with the patient or their family, and work out routines aimed at reducing general distress. High RD can be remedied by changing treatment regimen, decreased EB - by conducting a series of motivational talks, and decreased PD - by improving the patient-physician relations. In general, the questionnaire helps to detect areas within which support should be provided to the patient. In earlier studies on the subject, it was observed that psychoeducation provided to diabetes patients already at the stage of initial treatment in Primary Care helps reduce the overall level of distress. $^{21}$

\section{Conclusion}

The DDS scale can be successfully used for the assessment of distress in the Polish population of diabetes patients. The Polish version Diabetes Distress Scale can be used for diagnostic and clinical.

\section{Disclosure}

The authors report no conflicts of interest in this work.

\section{References}

1. IDF. Diabetes atlas 9. Available from: https://www.diabetesatlas.org/ upload/resources/material/20200302_133351_IDFATLAS9e-finalweb.pdf. Accessed 20, 2020.

2. Franks MM, Lucas T, Stephens MAP, Rook KS, Gonzalez R. Diabetes distress and depressive symptoms: a dyadic investigation of older patients and their spouses. Fam Relat. 2010;59:599-610. doi:10.1111/j.1741-3729.2010.00626.x

3. Polonsky WH, Anderson BJ, Lohrer PA, et al. Assessment of diabetes-related distress. Diabetes Care. 1995;18(6):754-760. PMID: 7555499. doi:10.2337/diacare.18.6.754

4. Thanakwang K, Thinganjana W, Konggumnerd R. Psychometric properties of the Thai version of the diabetes distress scale in diabetic seniors. Clin Interv Aging. 2014;9:1353-1361. doi:10.2147/CIA.S67200

5. Fisher L, Hessler DM, Polonsky WH, Mullan JT. When is diabetes distress clinically meaningful?: establishing cut points for the diabetes distress scale. Diabetes Care. 2012;35(2):259-264. doi:10.2337/dc11-1572

6. Fisher L, Skaff MM, Mullan JT, et al. Clinical depression versus distress among patients with type 2 diabetes: not just a question of semantics. Diabetes Care. 2007;30(3):542-548. doi:10.2337/dc06-1614

7. Grigsby AB, Anderson RJ, Freedland KE, Clouse RE, Lustman PJ. Presence of anxiety in adults with diabetes: a systematic review.J. Psychosom Res. 2002;53:1053-1060. doi:10.1016/S0022-3999(02) 00417-8

8. Polonsky WH, Fisher L, Earles J, et al. Assessing psychosocial distress in diabetes: development of the diabetes distress scale. Diabetes Care. 2005;28(3):626-631. PMID: 15735199. doi:10.2337/diacare.28.3.626

9. Herschbach P, Duran G, Waadt S, Zettler A, Amm C, Marten-Mittag B. Psychometric properties of the Questionnaire on Stress in patients with Diabetes-Revised (QSD-R). Health Psychol. 1997;16 (2):171-174. PMID: 9269888. doi:10.1037/0278-6133.16.2.171

10. Gonzalez JS, Fisher L, Polonsky WH. Depression in diabetes: have we been missing something important? Diabetes Care. 2011;34 (1):236-239. doi:10.2337/dc10-1970

11. Snoek FJ, Pouwer F, Welch GW, Polonsky WH. Diabetes-related emotional distress in Dutch and U.S. diabetic patients: cross-cultural validity of the problem areas in diabetes scale. Diabetes Care. 2000;23 (9):1305-1309. doi:10.2337/diacare.23.9.1305

12. Joensen LE, Tapager I, Willaing I. Diabetes distress in type 1 diabetes - a new measurement fit for purpose. Diabetic Med. 2013;30 (9):1132-1139. doi:10.1111/dme.12241

13. Graue M, Haugstvedt A, Wentzel-Larsen T, Iversen MM, Karlsen B, Rokne B. Diabetes-related emotional distress in adults: reliability and validity of Norwegian versions of the Problem Areas in Diabetes Scale (PAID) and the Diabetes Distress Scale (DDS). Int J Nurs Stud. 2012;49(2):174-182. doi:10.1016/j.ijnurstu.2011.08.007

14. Ting RZ, Nan H, Yu MW, et al. Diabetes-related distress and physical and psychological health in chinese type 2 diabetic patients. Diabetes Care. 2011;34(5):1094-1096. PMID: 21398526; PMCID: PMC3114496. doi:10.2337/dc10-1612

15. $\mathrm{R}$ Core Team. $R: A$ Language and Environment for Statistical Computing. Vienna, Austria: $\mathrm{R}$ Foundation for Statistical Computing; 2018. Available from: https://www.R-project.org/. Accessed July 20, 2021.

16. Ware JE Jr, Gandek B. Metody testowania jakości danych, założeń skalowania i niezawodności: podejście projektowe IQOLA. J Clin Epidemiol. 1998;51(11):945-952. doi:10.1016/S0895-4356(98) 00085-7

17. Chew BH, Mukhtar F, Sherina MS, Paimin F, Hassan NH, Jamaludin NK. The reliability and validity of the malay version 17-item diabetes distress scale. Malays Fam Physician. 2015;10 (2):22-35. PMID: 27099658; PMCID: PMC4826578. 
18. Martinez-Vega IP, Doubova SV, Aguirre-Hernandez R, InfanteCastaneda C. Adaptation and validation of the distress scale for Mexican patients with type 2 diabetes and hypertension: a cross-sectional survey. BMJ Open. 2016;6(3):e009723. doi:10.1136/ bmjopen-2015-009723

19. Farm BA, Perwitasari DA, Thobari JA, Cao Q, Krabbe PF, Postma MJ. Translation, revision, and validation of the diabetes distress scale for indonesian type 2 diabetic outpatients with various types of complications. Value Health Reg Issues. 2017;12:63-73. doi:10.1016/j.vhri.2017.03.010
20. Ortiz MS, Baeza-Rivera MJ, Myers HF. Propiedades Psicométricas de la Escala de Estrés para Diabéticos En una Muestra de Pacientes Diabéticos Tipo II Chilenos. Ter Psicol. 2013;31:281-286. Galician. doi:10.4067/S0718-48082013000300002

21. Fisher L, Gonzalez JS, Polonsky WH. The confusing tale of depression and distress in patients with diabetes: a call for greater clarity and precision. Diabet Med. 2014;31(7):764-772. doi:10.1111/ dme. 12428

\section{Publish your work in this journal}

Psychology Research and Behavior Management is an international, peer-reviewed, open access journal focusing on the science of psychology and its application in behavior management to develop improved outcomes in the clinical, educational, sports and business arenas. Specific topics covered in the journal include: Neuroscience, memory and decision making; Behavior modification and management; Clinical applications; Business and sports performance management; Social and developmental studies; Animal studies. The manuscript management system is completely online and includes a very quick and fair peer-review system, which is all easy to use. Visit http://www. dovepress.com/testimonials.php to read real quotes from published authors. 